\title{
$\mathrm{Se}$ 전구체 함량 따른 $\mathrm{CdSe}$ 양자점 형광체의 발광특성
}

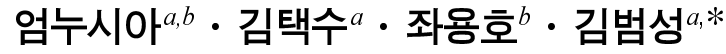 \\ ${ }^{a}$ 한국생산기술연구원 희소금속연구그룹, ${ }^{b}$ 한양대학교 기능성 나노재료 연구실
}

\section{Luminescent Characteristics of CdSe Quantum Dot Phosphor Depending on Se Precursor Ratio}

\author{
Nu Si A Eom ${ }^{a, b}$, Taek-Soo Kim ${ }^{a}$, Yong-Ho Choa ${ }^{b}$ and Bum Sung Kim ${ }^{a, *}$ \\ ${ }^{a}$ Korea Institute of Industrial Technology, 7-47, Songdo-Dong, Yeonsu-gu, Incheon 406-840, Korea \\ ${ }^{b}$ Functional Nano Material Research Lab., Hanyang University, Ansan 426-791, Korea \\ (Received November 6, 2012; Revised November 22, 2012; Accepted December 6, 2012)
}

\begin{abstract}
The quantum dots (QD) have unique electrical and optical properties due to quantum dot confinement effect. The optical properties of QDs are decided by various synthesis conditions. In a prior QDs study, a study on the QDs size with synthesis condition such as synthesis time and temperature is being extensively researched. However, the research on QDs size with composition ratio has hitherto received scant attention. In order to evaluate the ratio dependence of CdSe crystal, synthesis ratio of Se precursor is changed from $16.7 \mathrm{~mol} \% \mathrm{Se}$ to $44 \mathrm{~mol} \% \mathrm{Se}$. As the increasing Se ratio, the band gap was increased. This is caused by red shift of emission. We confirmed optical property of CdSe QDs with composition ratio.
\end{abstract}

Keywords: Quantum dot (QD), CdSe, Photoluminescence

\section{1. 서 론}

최근 나노물질의 독특한 물리적 화학적 특성과 다양한 분야로의 응용 가능한 기대로 인해[1] 고효율, 고품질의 양자점 형광체 합성 연구가 활발히 진행되고 있다. 양자점 형광체는 크기가 작아짐에 따라 양자구속 효과에 의해 가 전자대와 전도대 사이의 간격인 밴드갭이 늘어나 흡수 및 방출 파장의 변화를 유도하게 된다. 입자 크기가 다른 양 자점 형광체는 양자구속효과를 통해 모든 가시광 영역의 빛을 구현할 수 있어 LED[2], 바이오 센서[3], 태양전지[4] 와 같은 분야에서 적용된다. 그 중 $\mathrm{CdSe}$ 양자점은 넓은 흡 수파장대, 높은 발광효율, 좁은 발광 반가폭 뿐만 아니라[5] $1.72 \mathrm{eV}[6]$ 의 밴드갭을 갖기 때문에 모든 가시광 영역의 빛을 낼 수 있는 소재로서 현재까지 가장 많은 연구가 진 행되어 왔다[7]. 양자점 형광체는 주로 좁은 입도분포의 양자점 형광체를 합성할 수 있는 콜로이드 법에 의해 합 성되며 $[8,9]$, 이 방법으로 합성된 양자점은 전구체의 종류
와 농도, 성장온도 등을 제어함으로써 다양한 특성을 나타 낸다. 기존의 양자점 형광체 연구에서는 양자구속 효과에 의한 합성시간, 온도에 관한 연구가 활발히 진행되어 왔으 나, 조성비에 따른 크기에 관한 연구는 부족한 실정이다. 양자점 형광체의 합성물질의 조성비는 합성된 양자점의 크기 및 밴드갭의 영향을 주기 때문에 조성비와 관련된 연구개발이 더욱 요구되고 있다.

본 연구에서는 $\mathrm{Se}$ 조성변화에 따른 $\mathrm{CdSe}$ 양자점의 발광 특성을 확인하기 위하여 $\mathrm{Se}$ 의 조성을 $\mathrm{Cd}$ 대비 $\mathrm{Se}$ 의 함량 을 $5: 1,5: 2,5: 4$ 의 변화를 주어 콜로이드 법으로 합성하였 다. 또한 시간에 따른 $\mathrm{Se}$ 함량에 따른 양자점의 합성과 성 장거동을 이해하기 위하여 합성시간을 변수로 실험을 수 행하였다

\section{2. 실험방법}

본 연구에서는 $\mathrm{CdSe}$ 양자점을 합성하기 위하여 출발 물

*Corresponding Author : Bum Sung Kim, TEL: +82-32-850-0286-, FAX: +82-32-850-0304, E-mail: bskim15@kitech.re.kr 
질로 $\mathrm{Cd}$ 전구체로서 $\mathrm{CdO}(99.99 \%$, Sigma Aldrich), $\mathrm{Se}$ 전 구체로서 Se 분말(99.99\%, Sigma Aldrich)을 사용하였다. 용매로는 1-octadecene( $90 \%$, Sigma Aldrich)을 사용하였으 며, 캡핑 에이전트(capping agent)로는 올레인 산(Oleic acid, $\mathrm{C}_{17} \mathrm{H}_{33} \mathrm{COH}, 90 \%$, Sigma Aldrich)을 선택하였다. $\mathrm{CdSe}$ 양자점을 합성하기 위해 $\mathrm{CdO}$ 와 1-octadecene, 올레 인 산을 용해시켜 $\mathrm{Cd}$ 전구체를 얻었고, $\mathrm{Se}$ 전구체로서 $\mathrm{Se}$ 분말과 1-octadecene을 아르곤(Ar) 가스 분위기 하에서 혼 합용액이 투명해질 때까지 가열하였다. 반응시키고자 하 는 온도 $\left(270^{\circ} \mathrm{C}\right)$ 로 변화를 주어 $\mathrm{Cd}$ 전구체를 $\mathrm{Se}$ 함량비 $(\mathrm{Cd}: \mathrm{Se}=5: 1(16.7 \mathrm{~mol} \% \mathrm{Se}), 5: 2(28.6 \mathrm{~mol} \% \mathrm{Se}), 5: 4(44 \mathrm{~mol} \% \mathrm{Se}))$ 에 따라 빠르게 투입시킨 후 $\mathrm{Se}$ 함량조건에 따른 입자성 장을 관찰하기 위하여 10 분, 20 분, 30 분, 60 분 반응시켰다. 합성된 $\mathrm{CdSe}$ 양자점은 특성 분석을 위하여, 비극성 용매 인 헥산(hexane, $\mathrm{CH}_{3}\left(\mathrm{CH}_{2}\right)_{4} \mathrm{CH}_{3}$, Guaranteed pure, JUNSEI)에 콜로이드 상태로 분산시켰다. 조건에 따라 합성된 $\mathrm{CdSe}$ 양자점의 흡광 특성은 UV-visible spectroscopy (Optizen 2120 UV, Mecasys Co., Korea)을 이용하여 측정하였고, 발광특성은 Photoluminescence(DM320, Dongwoo optron. Co., Korea)을 사용하여 관찰하였다. XRD의 회절 패턴을 통해 상 분석을 하여 $\mathrm{CdSe}$ 양자점의 합성 및 상변화를 확 인하였다. TEM(JEM-4010, JEOL, Japan)분석은 $400 \mathrm{kV}$ 인 고분해능 투과 전자 현미경을 사용하여 입자의 형상 및 크기를 파악하였다. TEM분석에 사용될 시료는 헥산에 분 산시킨 양자점을 구리 그리드(copper grid) 위에 떨어트린 후 진공에서 건조시켜서 준비하였다.

\section{3. 결과 및 고찰}

그림 1 은 합성시간과 $\mathrm{Se}$ 함량 변수에 따라 합성한 양자 점 형광체의 흡수 및 발광 스펙트럼이다. 그림 $1(\mathrm{a})$ 의 $\mathrm{Cd}$ 와 $\mathrm{Se}$ 의 비율이 $5: 1$ 일때 합성 초기 10 분, 20 분에는 발광피
크는 넓게 분포되어 있으며 UV-Vis는 분해능이 좋지 않게 나타났다. 합성시간이 30 분이 경과하면서 흡수 및 발광스 펙트럼의 피크가 명확하게 구분되었으며, 합성 초기와 비 교하여 합성시간 60 분에는 발광피크는 좁게 형성되어있다. $\mathrm{Cd}$ 와 $\mathrm{Se}$ 의 비율이 $5: 2$ 로 증가한 그림 $1(\mathrm{~b})$ 의 경우 최단 반 응시간인 10 분에서 발광스펙트럼의 피크가 넓게 형성되어 있으나 합성시간 20 분으로 증가함에 따라 좁은 발광피크 가 나타난다. 그림 1(c)에서는 모든 반응시간 조건에서 발 광파장의 피크가 좁게 형성되어 있으며 이는 $\mathrm{Cd}$ 와 $\mathrm{Se}$ 의 비율이 5:4로 증가함에 따라 입자 크기가 균일하게 분포 효과가 발생한 것으로 판단된다. 모든 $\mathrm{Se}$ 함량비의 합성 결과에서 $\mathrm{CdSe}$ 합성시간이 증가함에 따라 장파장 이동을 확인할 수 있으며, 이러한 장파장 이동을 통해서 입자 성 장을 예상할 수 있다. 합성시간이 증가함에 따라 발광파장 의 피크가 좁아지는 것은 입자 성장은 포화농도에 도달하 기까지 진행되는 오스왈드 숙성(Ostwald ripening)에 의한 것으로 판단된다[10].

합성된 양자점은 동일한 시간에서 합성농도를 변수로 주었을 때에 $\mathrm{Se}$ 의 비율이 증가할수록 양자점의 흡수 및 발광 최대파장이 장파장으로 이동하였다. 합성시간 10 분 의 그림 1(a)에서는 $560 \mathrm{~nm}$, 그림 1(b)에서는 $580 \mathrm{~nm}$, 그림 1(c)에서는 $605 \mathrm{~nm}$ 의 발광파장을 갖으며, $\mathrm{Se}$ 함량비 가 증가할수록 장파장 이동이 확인되었다. 그러나 합성시 간 60 분에서는 모든 $\mathrm{Se}$ 함량조건의 $\mathrm{CdSe}$ 의 발광파장이 $650 \mathrm{~nm}$ 으로 나타나며 $\mathrm{Se}$ 함량비에 상관없이 같은 파장 의 발광이 나타났다. $\mathrm{Se}$ 함량비가 가장 작은 그림 $1(\mathrm{a})$ 에 서는 시간이 증가함에 따라 560 650 nm 파장의 넓은 가 시광선 파장 범위에서 발광하는 반면 그림 1(c)에서 $607 \sim 650 \mathrm{~nm}$ 파장은 좁은 범위의 발광이 확인되었다. 합 성시간이 증가함에 따라 입자 성장에 의해 양자구속 효과 특성으로 장파장 이동이 발생하지만, 밴드갭이 큰 $\mathrm{Se}$ 의 함 량비가 증가하면 발광파장 범위가 감소한다. 결과적으로,
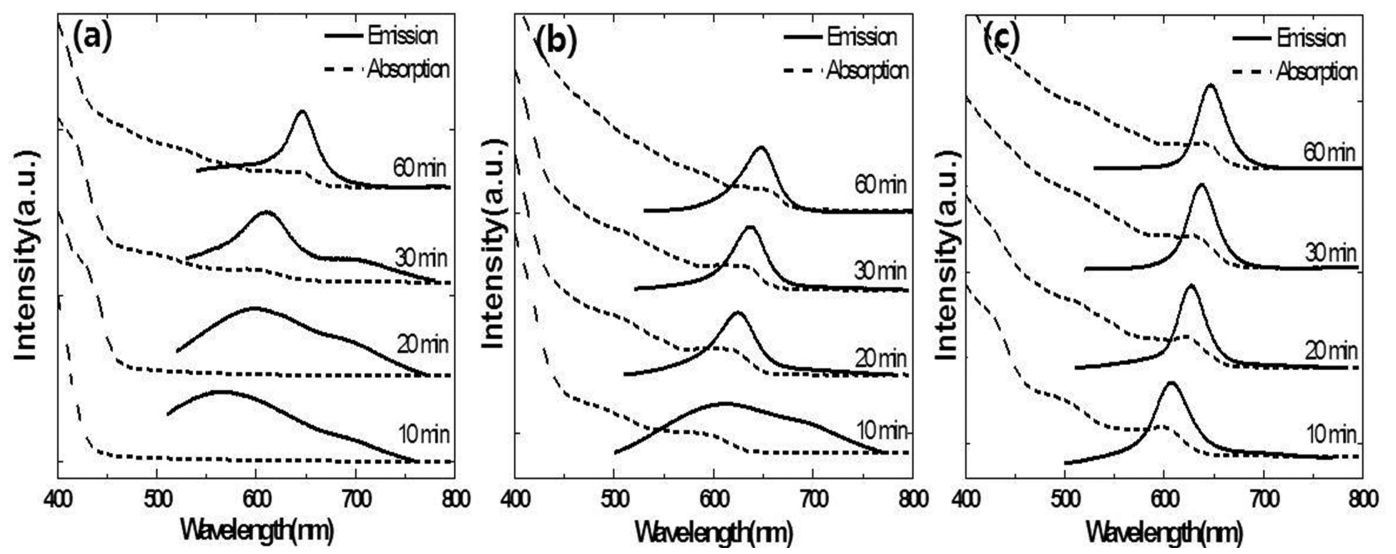

Fig. 1. UV-visible absorbance and PL emission spectra of CdSe quantum dot with synthesis conditions (a) Cd:Se=5:1 (16.7 mol\%Se) (b) 5:2 (28.6 mol\%Se) (c) 5:4 (44 mol\% Se). 

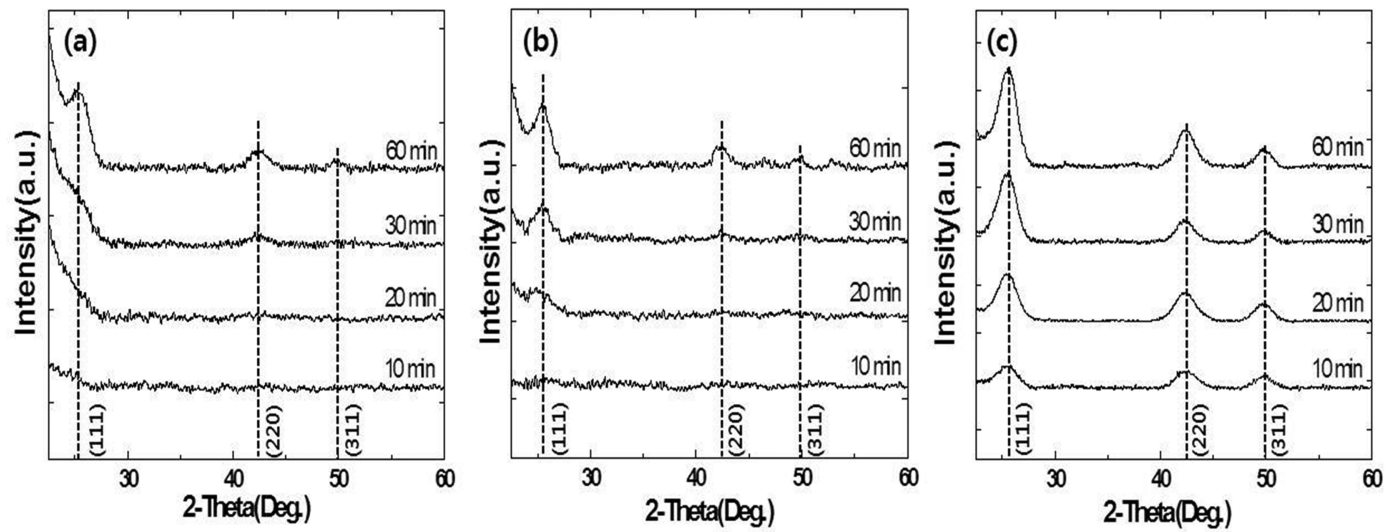

Fig. 2. XRD patterns of CdSe quantum dot with synthesis conditions. (a) Cd:Se=5:1 (16.7 mol\%Se) (b) 5:2 (28.6 mol\%Se) (c) 5:4 (44 mol\%Se).

$\mathrm{CdSe}$ 양자점 형광체의 광범위한 가시광선 영역의 발광을 위해서는 $\mathrm{Se}$ 의 함량을 감소시키는 것이 유리한 합성조건 임을 확인 할 수 있었다.

흡광발광 파장에서 뚜렷한 광학특성을 나타내지 않는 합성초기를 포함한 모든 양자점 형광체의 $\mathrm{CdSe}$ 양자점 형 광체의 상 확인을 위해 XRD 분석을 실시하였다. 그림 2 는 합성시간과 $\mathrm{Se}$ 함량에 따라 합성된 $\mathrm{CdSe}$ 양자점 형광 체의 상분석을 위한 XRD 패턴이다. X-ray 패턴에서 (111), (220), (311)면에 해당하는 3개의 뚜렷한 회절피크가 나타나는데 JCPDS[19-0191]의 데이터와 일치함으로써 결 정질 $\mathrm{CdSe}$ 양자점의 합성을 확인할 수 있었다[11]. 합성 시간이 증가할수록 입자 성장에 의해 XRD 피크 강도는 증가하였고, $\mathrm{Se}$ 함량이 증가할수록 $\mathrm{XRD}$ 강도가 증가하여 결정성의 증가를 확인할 수 있었다. $\mathrm{Se}$ 함량이 16.7 $\mathrm{mol} \% \mathrm{Se}(\mathrm{Cd}: \mathrm{Se}=5: 1), 28.6 \mathrm{~mol} \% \mathrm{Se}(\mathrm{Cd}: \mathrm{Se}:=5: 2)$ 는 초기에 는 XRD 패턴이 확인되지 않았고, $\mathrm{Se}$ 함량이 $16.7 \mathrm{~mol} \% \mathrm{Se}$ $(\mathrm{Cd}: \mathrm{Se}=5: 1)$ 은 60 분 이상 성장 시켰을 때, $\mathrm{Se}$ 함량이 28.6 $\mathrm{mol} \% \mathrm{Se}(\mathrm{Cd}: \mathrm{Se}=5: 1)$ 은 30 분 이상 성장 시켰을 때 뚜렷한 $\mathrm{XRD}$ 패턴이 확인되었다. 합성조건 $44 \mathrm{~mol} \% \mathrm{Se}(\mathrm{Cd}: \mathrm{Se}=5: 1)$ 의 경우 합성 초기부터 모든 합성시간에서 뚜렷한 XRD 패턴을 관찰 할 수 있었다. 합성된 모든 양자점 형광체는 합성 초기와 비교하여 합성시간이 증가함에 따라 입자 성 장 및 결정성에 의해 XRD 강도가 증가하였으며, 합성 함 량과 시간에 따른 상변화는 나타나지 않았다.

이상의 그림 2 의 결과는 그림 1 의 광학특성과 동일하게 $\mathrm{Se}$ 함량이 적고 합성시간이 짧을수록 뚜렷한 양자점 피크 가 확인되지 않았다. 모든 $\mathrm{Se}$ 함량의 합성조건에서 합성 시간 10 분을 비교하면 $\mathrm{Se}$ 함량비에 따른 $\mathrm{CdSe}$ 양자점 형 광체의 광학특성와 결정성의 차이가 뚜렷하게 확인됨을 알 수 있었다.

이러한 $\mathrm{Se}$ 함량비에 따른 입자 크기 및 결정성의 차이 를 자세히 확인하기 위하여 광학특성에 뚜렷한 차이를 보
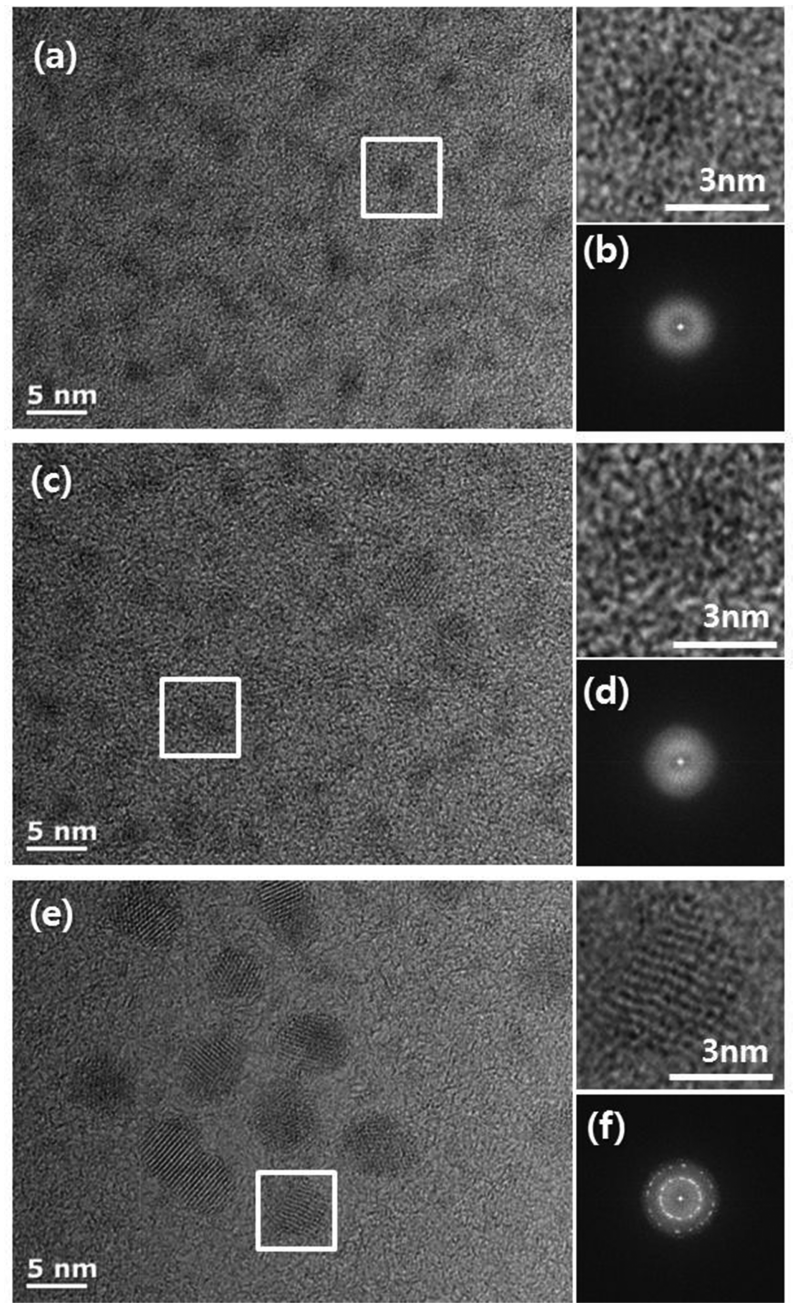

Fig. 3. TEM and FFT image show that morphology with ratio of Cd:Se. TEM image (a) $\mathrm{Cd}: \mathrm{Se}=5: 1(16.7 \mathrm{~mol} \% \mathrm{Se})$ (c) 5:2 (28.6 mol\%Se) (e) 5:4 (44 mol\%Se). FFT image (b) Cd:Se=5:1 (16.7 mol\%Se) (d) 5:2 (28.6 mol\%Se) (f) 5:4 (44 mol\%Se).

이는 합성시간 10 분에서 $\mathrm{Se}$ 함량에 따른 양자점 형광체의 $\mathrm{TEM}$ 이미지를 그림 3에 나타냈다. 합성된 양자점의 $\mathrm{Se}$ 함 
량비가 $\mathrm{Cd}: \mathrm{Se}=5: 1$ (그림 3(a))과 5:2 (그림 3(c))의 경우 약 $2 \sim 3 \mathrm{~nm}$ 의 크기의 양자점을 확인할 수 있었으며, 그림 3(b), (d)의 FFT(Fast Fourier Transform) 이미지에서 결정 성이 확인되지 않았다. 또한 그림 3(e)에서는 $\mathrm{Cd}: \mathrm{Se}=5: 4$ 의 $\mathrm{Se}$ 함량비의 양자점 형광체의 격자무늬가 관찰이 되었고 약 $5 \mathrm{~nm}$ 의 크기로 균일하게 분산되어 있음을 확인할 수 있었다. 또한, 그림 3(f)의 FFT 이미지 결과에서 명확한 결 정성을 가지고 있음을 확인할 수 있었다. 입자크기에 따른 밴드갭과 $\mathrm{Se}$ 함량의 변화는 분리하여 설명하기 어렵다. $5: 1,5: 2$ 의 경우 $\mathrm{TEM}$ 이미지에서는 유사한 입자크기를 가 지나 파장이동이 발생하였다. 이는 동일한 합성시간에서 $\mathrm{Se}$ 의 함량에 따른 발광파장의 변화는 $\mathrm{Se}$ 의 밴드갭으로 설 명이 가능하다. $\mathrm{Se}$ 함량 변수에서 $\mathrm{Se}$ 와 $\mathrm{Cd}$ 의 밴드갭의 차 이에 의해 밴드갭이 큰 $\mathrm{Se}$ 의 비율이 증가할수록 장파장으 로 이동한다. 5:4의 경우 입자 성장도 확인되며 $\mathrm{Se}$ 함량변 화와 입자크기변화가 동반된 것으로 사료된다.

\section{4. 결 론}

본 연구에서는 $\mathrm{Cd}$ 와 $\mathrm{Se}$ 의 비율이 제어된 $\mathrm{CdSe}$ 양자점 형광체를 합성하여 발광특성과 결정학적 특성을 평가하고 미세구조를 관찰하였다. 합성에 투입된 $\mathrm{Cd}$ 대비 $\mathrm{Se}$ 의 함 량이 $5: 1$ 에서 $5: 4$ 로 증가함에 따라 명확한 광학적, 결정학 적 양자점 형광체 거동을 발현하는 형광체의 합성시간이 단축됨을 확인할 수 있었다. 모든 $\mathrm{Se}$ 함량비율의 실험에 서 합성 시간이 증가함에 따라 $\mathrm{CdSe}$ 의 성장에 의해 밴드 갭의 증가현상이 관찰되었고 합성된 양자점 형광체는 $550 \sim 650 \mathrm{~nm}$ 파장 범위에서 발광특성을 보였다. 투과전자 현미경으로 관찰한 미세구조 분석 결과 합성된 양자점의 크기는 2 5 nm 크기의 범위를 가지고 있었으며 상대적으 로 짧은 반응시간 동안 합성된 양자점은 장시간 합성한 양자점에 비해 넓은 범위의 크기 분포를 의미하는 넓은
분포의 발광특성을 발현하였다. 이상의 실험 결과를 통해 기존의 온도 및 시간에 따른 입자성장의 양자구속효과뿐 아니라 양자점의 조성이 미치는 입자크기 및 밴드갭의 영 향을 확인하였다.

\section{감사의 글}

본 연구는 한국생산기술연구원의 희소금속산업 육성인 프라 기반구축사업(과제번호: N000600001)의 지원을 받 아 수행되었으며 이에 감사드립니다.

\section{참고문헌}

[1] S. J. Sim, K. K. Cho and Y. Y. Kim: J. Kor. Powd. Met. Inst., 18 (2011) 1 (Korean).

[2] S. Coe, W. K. Woo, M. Bawendi and V. Bulovic: Nature. 420 (2002) 800.

[3] B. Dubertert, P. Skourides, D. J. Norris, V. Noireaux, A. H. Brivanlou and A. Libchaber: Science., 298 (2002) 1759.

[4] W. U. Huynh, X. G. Peng and A. P. Alivisatos: Adv. Mater., 11 (1999) 923.

[5] W. K. Chung, H. J. Yu, S. H. Park, B. H. Chun and S. H. Kim: J. Kor. Chem. Eng. Res., 49 (2011) 320 (Korean).

[6] M. Kumar and M. Sharon: Thin solid films., 312 (1998) 139.

[7] N. S. A. Eom, T. S. Kim, Y. H. Choa and B. S. Kim: J. Kor. Mater. Res., 22 (2012) 140 (Korean).

[8] Z. A. Peng and X. Peng: J. Am. Chem. Soc., 123 (2001) 183.

[9] L. Qu, Z. A. Peng and X. Peng: Nano Lett., 1 (2001) 333.

[10] Y. A. Yang, H. M. Wu, K. R. Williams and Y. C. Cao: Angew. Chem. Int. Ed., 44 (2005) 6712.

[11] C. Zhai, H. Zhang, N. Du, B. Chen, H. Huang, Y. Wu and D. Yang: Nanoscale Res Lett., 6 (2011) 31. 